\title{
Diversity of Eukaryotic Algae in Propylene Oxide Saponification Wastewater Activated Sludge
}

\author{
Rong $\mathrm{He}^{1} \cdot$ Xiangyu Fan ${ }^{1} \cdot$ Pengfei Gu${ }^{1} \cdot \operatorname{Yan}_{\mathrm{Ji}^{1}}{ }^{1} \mathrm{Junyu}_{\text {Shen }}{ }^{1} \cdot$ \\ Ruirui $\mathrm{Li}^{1}$ - Yumei $\mathbf{L i}^{1} \cdot$ Qiang $\mathbf{L i}^{1}{ }^{1}$
}

Received: 31 January 2017 /Revised: 25 February 2017 / Accepted: 27 February 2017 /Published online: 11 April 2017

(C) Springer Science+Business Media Singapore 2017

\begin{abstract}
Eukaryotic algae play an important role to maintain the energy cycle and provide oxygen in the ecosystem of water environment, such as rivers, lakes, and wastewater activated sludge. As one of the important microorganisms in the activated sludge, the community structure of eukaryotic algae in the activated sludge is still not clear. Activated sludge process had been successfully used to dispose the propylene oxide (PO) saponification wastewater, which was contaminated with high chemical oxygen demand (1200-1500 mg/L) and high chlorine concentration $(22000-26,000 \mathrm{mg} / \mathrm{L})$. In this study, we focused on the diversity of eukaryotic algae in the PO saponification wastewater and municipal wastewater treatment plant. Based on Illumina Miseq high-throughput sequencing, the algae could be divided into nine different groups for the municipal wastewater activated sludge. By contrast, the algae in the PO saponification wastewater activated sludge could be grouped into two unidentified groups, which were quite different from the municipal sludge. In order to further analyze the diversity of eukaryotic algae in the PO saponification wastewater activated sludge, $18 \mathrm{~S}$ rDNA clone library of eukaryotic algae was constructed, and 31 clones were obtained. On account of BLASTn analysis, one of them was identified as Desmodesmus intermedius, while others were considered as uncultured eukaryotic algae. Moreover, $D$. intermedius, which had the potential biodiesel-producing capacity, was successfully isolated from the PO saponification wastewater activated sludge. This study would open an avenue to understand the eukaryotic alage diversity and utilize the
\end{abstract}

Qiang Li

chm_liq@ujn.edu.cn

1 School of Biological Science and Technology, University of Jinan, Jinan 250022, People's Republic of China biodiesel-producing eukaryotic alage in the PO saponification wastewater activated sludge.

Keywords Illumina Miseq high-throughput sequencing $\cdot 18 \mathrm{~S}$ rDNA $\cdot$ Eukaryotic algae $\cdot$ Phylogeny $\cdot$ Activated sludge

\section{Introduction}

Activated sludge process has been widely applied to dispose wastewater since 1913 [1]. As the dominant component for the treatment of organic pollutants in the aeration tank, the activated sludge fundamentally determines the treatment capacity of sewage treatment plants [2]. The biological activity of activated sludge microorganisms mainly depends on the structure and function of microbial community [3]. In general, bacteria, archaea, fungi, protists, and eukaryotic algae are involved in the activated sludge, which could degrade various pollutants, including organic compounds, toxicants, and xenobiotics $[4,5]$.

As one of the important microorganisms in the activated sludge, eukaryotic algae is a kind of algae which has chlorophyll as its primary photosynthetic pigment and lacks a sterile covering of cells around those reproductive cells [6]. Eukaryotic algae play an important role in the flow of energy and nitrogen fixation in the activated sludge [7]. Furthermore, eukaryotic algae could act as primary producers in the ecosystem of the lake and take an important role in the entire food web energy cycle of water environment [8]. Cong Li reported that phagotrophic algae had the unique ability to survive by ingesting insoluble organic particles including microbial cells, and could recover organic matter of residual activated sludge into the biomass of phagotrophic algae [9]. Analysis of eukaryotic algae community in the activated 
sludge would provide us a better understanding of this useful microorganism.

The saponification wastewater from the process of PO production is contaminated with high chemical oxygen demand $(1200-1500 \mathrm{mg} / \mathrm{L})$ and chlorine concentration $(22000$ $26,000 \mathrm{mg} / \mathrm{L}$ ), and the activated sludge process had been successfully used to dispose the saponification wastewater [10]. High-throughput sequencing technology is an efficient tool to reveal the community structures of the activated sludge. Based on Illumina Miseq high-throughput sequencing, the bacterial community composition of $\mathrm{PO}$ wastewater activated sludge was proved to be quite different from the manicipal wastewater activated sludge (Results will be published in another paper).

In this research, Illumina Miseq high-throughput sequencing, and construction of $18 \mathrm{~S}$ rDNA clone library were used to analyze the eukaryotic algae communities in the PO saponification wastewater activated sludge. Moreover, the potential biodiesel-producing alage, Desmodesmus intermedius, was successfully isolated from the activated sludge. This study would offer a reference to understand the eukaryotic alage diversity and utilize the biodiesel-producing eukaryotic alage in the PO saponification wastewater activated sludge.

\section{Material and Methods}

\section{Activated Sludge Sampling}

Activated sludge samples used in this research were acquired from the aeration tank of a $\mathrm{PO}$ saponification wastewater treatment plant in Befar Group Co., Ltd., Shandong, China, and a municipal wastewater treatment plant in Jinan, China, respectively. Samples were taken in sterile polyethylene bottles, transported to the laboratory on ice, and stored at $4{ }^{\circ} \mathrm{C}$ in the refrigerator for the following experiments.

\section{DNA Extraction, PCR, and Illumina Miseq High-Throughput Sequencing (HTS)}

Activated sludge samples were centrifuged at $6000 \mathrm{~g}$ for $10 \mathrm{~min}$ at $4{ }^{\circ} \mathrm{C}$ to collect the sediments, and the supernatants were discarded. Genomic DNA of samples (concentration $\geq 10 \mathrm{ng} / \mu \mathrm{l}$, total amount of DNA $\geq 500 \mathrm{ng}$, OD260/280 $>1.80$ ) was extracted by E.Z.N.A.TM Soil DNA Kit of OMEGA. PCR was performed using $18 \mathrm{~S}$ universal primers: 18S-F (5'-ACCTGGTTGATCCTGCCAGT-3') and 18S-R (5'-TCACCTACGGAAACCTTGT-3'). PCR mixtures $(50 \mu \mathrm{l})$ were prepared in duplicate and each contained $2 \mu \mathrm{l}$ of DNA template, $5 \mu \mathrm{l}$ of $10 \times$ PCR buffer $(50 \mathrm{mM} \mathrm{KCl}, 10 \mathrm{mM}$ Tris- $\mathrm{HCl}$ and $1.5 \mathrm{mM} \mathrm{MgCl}_{2}$ ), $200 \mathrm{mM}$ of dNTP, $0.2 \mathrm{mM}$ of each primer, and $2.5 \mathrm{U}$ Taq polymerase (Promega, Madison, WI, USA). The PCR thermal regime consisted of an initial denaturation of $6 \mathrm{~min}$ at $94{ }^{\circ} \mathrm{C}$, followed by 30 cycles of $30 \mathrm{~s}$ at $94{ }^{\circ} \mathrm{C}, 30 \mathrm{~s}$ at $55^{\circ} \mathrm{C}, 150 \mathrm{~s}$ at $72{ }^{\circ} \mathrm{C}$, and a final cycle of 10 min at $72{ }^{\circ} \mathrm{C}$ [11]. PCR products were pooled and purified employing 0.8 volume of the AMPure XP Beads (Beckman). Finally, the DNA library was constructed and run on the Illumina Miseq at Shanghai Hanyu Biotech Co., Ltd.

The low-quality sequences and chimera were detected and removed by Mothur (version 1.32.01) and UCHIME (version 4.2.40), respectively. Operational taxonomic units (OTUs) were generated by Mothur (version 1.32.01) at the 97\% sequence similarity threshold. The taxonomic assignment was performed using the Ribosomal Database Project Classifier program with a confidence cutoff of $80 \%$. The eukaryotic algae taxa at the phylum, class, family, and genus level were analyzed, respectively.

\section{PCR, 18S rDNA Library Cloning and Sequencing}

Near-full-length eukaryotic $18 \mathrm{~S}$ rDNA were amplified using the 968F (5'- AAAGTTAGGGGATCG-3') and 1643R (5'CATTCAATCGGTAGG-3') specific eukaryotic primer set [12]. PCRs were performed with the following parameters: denaturation at $95^{\circ} \mathrm{C}$ for $5 \mathrm{~min}, 35$ cycles of denaturation at $94^{\circ} \mathrm{C}$ for $45 \mathrm{~s}$, annealing at $53.5^{\circ} \mathrm{C}$ for $45 \mathrm{~s}$, extension at $72{ }^{\circ} \mathrm{C}$ for $45 \mathrm{~s}$, and a final extension at $72^{\circ} \mathrm{C}$ for $7 \mathrm{~min}$ [12]. PCR products were then electrophoresed in $1 \%$ agarose at $100 \mathrm{~V}$ for $30 \mathrm{~min}$. The buffer was $1 \times$ Tris-acetate-EDTA, and $\mathrm{pH}$ was adjusted to 8.0.

PCR products were purified with the Gel Extraction kit (OMEGA BIO-TEK) and cloned with the pGM-T Ligation Kit (TIANGEN). The resulting recombinant vectors were then transformed into the competent cells of Escherichia coli JM109 (Promega). Thirty-one positive clones (white colonies) from each library were picked randomly. Plasmid DNAs of these colones were extracted by plasmid miniprep kit (BIOMIGA). At last, these clones were sequenced in a commercial company (BIOSUNE, Shanghai, China).

\section{Phylogenetic Analysis}

The sequences were subjected to BLASTn searching (http://BLAST.ncbi.nlm.nih.gov/BLAST.cgi). A rooted neighbor-joining tree was achieved by MEGA (version4.0) with 1,000-fold bootstrap support, and an unrooted phylogenetic tree was drawn using the interactive Tree of Life online program based on the distance matrix data calculated by MEGA 4.0 [13].

\section{Isolation and Purification of Microalgae}

Artificial seawater medium (F/2 medium) was used to incubate the eukaryotic algae. Agar plates and micropipettes were employed to isolate the algae. Each purified strain was initially cultured in a test tube $(30 \mathrm{ml})$ at $25 \pm 1{ }^{\circ} \mathrm{C}$ under continuous illumination of white fluorescent light at an intensity of 
$70 \mu \mathrm{mol} \mathrm{s}{ }^{-1} \mathrm{~m}^{-2}$ for 1 to 3 weeks. The algae were then incubated into a $100 \mathrm{ml}$ flask with sterile air at $25 \pm 1{ }^{\circ} \mathrm{C}$ under an intensity of $80 \mu \mathrm{mol} \mathrm{s}^{-1} \mathrm{~m}^{-2}$ for 10 days [14].

\section{Results and Discussion}

\section{Illumina Miseq High-Throughput Sequencing Analysis of Algae Community in Two Kinds of Activated Sludge}

In order to study the role of eukaryotic algae and community structure in the activated sludge, two kinds of activated sludge were acquired from PO saponification wastewater and municipal wastewater treatment plant, respectively. The metagenomics were extracted from two different activated sludge and then $18 \mathrm{~S}$ rDNA were sequenced through Illumina Miseq high-throughput sequencing. After removal of low-quality sequences and chimeras, the average number of Clean Reads for the PO saponification wastewater activated sludge genome was 22,101 , while the municipal wastewater activated sludge genome was 21,116 . The results of OTU cluster analysis using mothur were 21,969 OTUs, and 38 species belonged to eukaryotic algae. Phylogenetic tree analysis of 38 OTUs cluster revealed that the eukaryotic algae in the municipal wastewater activated sludge were divided into nine different groups (Fig. 1). Five of these groups were assigned to Ostreococcus, Symbiodinium, Anurofeca, Lotharella, and Thalassiosira, and the other four groups were unidentified eukaryotic algae. By contrast, the algae in the PO saponification wastewater activated sludge could be grouped into two unidentified groups, which were quite different from the municipal sludge. The sequencing data were deposited in NCBI, and the ID of the sequence was PRJNA361045 (SRP098945).

\section{Phylogeny of 18S rDNA Clones}

To further analyzed the diversity of eukaryotic algae in the activated sludge of PO saponification wastewater, a pair of primers based on 18S rDNA hypervariable regions were selected, which could not be used for high throughput sequencing. So $18 \mathrm{~S}$ rDNA clone library technology was used for the following steps.
Fig. 1 Phylogenetic analysis of 38 OTUs eukaryotic algae in the activated sludge

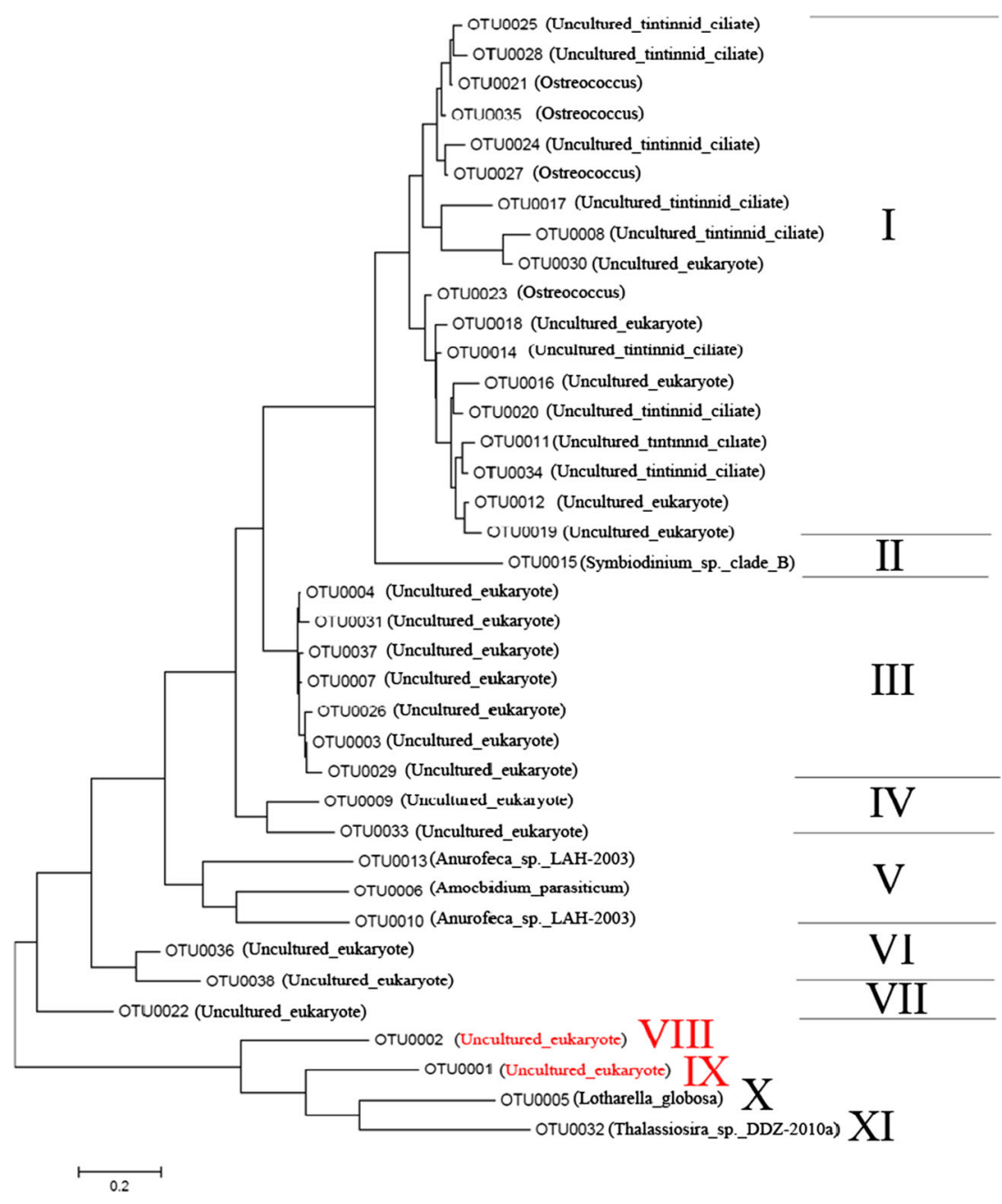


Fig. 2 The cloning of eukaryotic algae $18 \mathrm{~S}$ rDNA fragments. a Gel electrophoresis of PCR-amplified $18 \mathrm{~S}$ rDNA fragments from activated sludge. b Gel electrophoresis of PCR-amplified 18S rDNA fragments from plasmids. AS $1-$ 31 represents PCR-amplified $18 \mathrm{~S}$ rDNA fragments from different plasmids

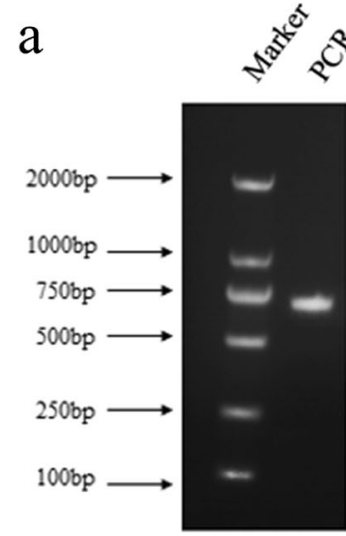

b

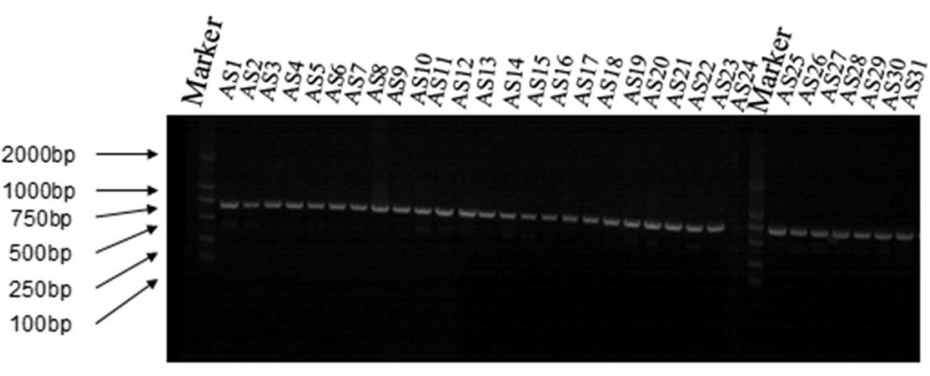

In this study, a pair of primers named $968 \mathrm{~F}$ and $1643 \mathrm{R}$ were employed, which was specifically used for eukaryotic algae community [12]. The metagenomic DNA extracted from the activated sludge was taken as template for PCR amplification. The $700 \mathrm{bp}$ DNA bands were exhibited in agarose gel electrophoresis (Fig. 2a). The result is consistent with a previous study [12], demonstrating the existence of eukaryotic algae in the activated sludge. Furthermore, we constructed clone libraries of the purified PCR products by inserting the purified DNA into the pGM-T plasmid vector and transforming into the competent cells of Escherichia coli JM109 cells. Altogether, 31 positive clones were selected and were amplified with the primers $968 \mathrm{~F}$ and 1643R. DNA bands around $700 \mathrm{bp}$ were appeared in all clones (Fig. 2b), which illustrated that target fragments were contained in all positive clones.

Afterwards, the sequenced 18S rDNA were searched using BLASTn program in the National Center for Biotechnology
Fig. 3 Neighbor-joining phylogenetic tree of $18 \mathrm{~S}$ rDNA sequences obtained in this study. $\star$ represent the eukaryotic algae which was isolated from PO saponification wastewater treatment activated sludge

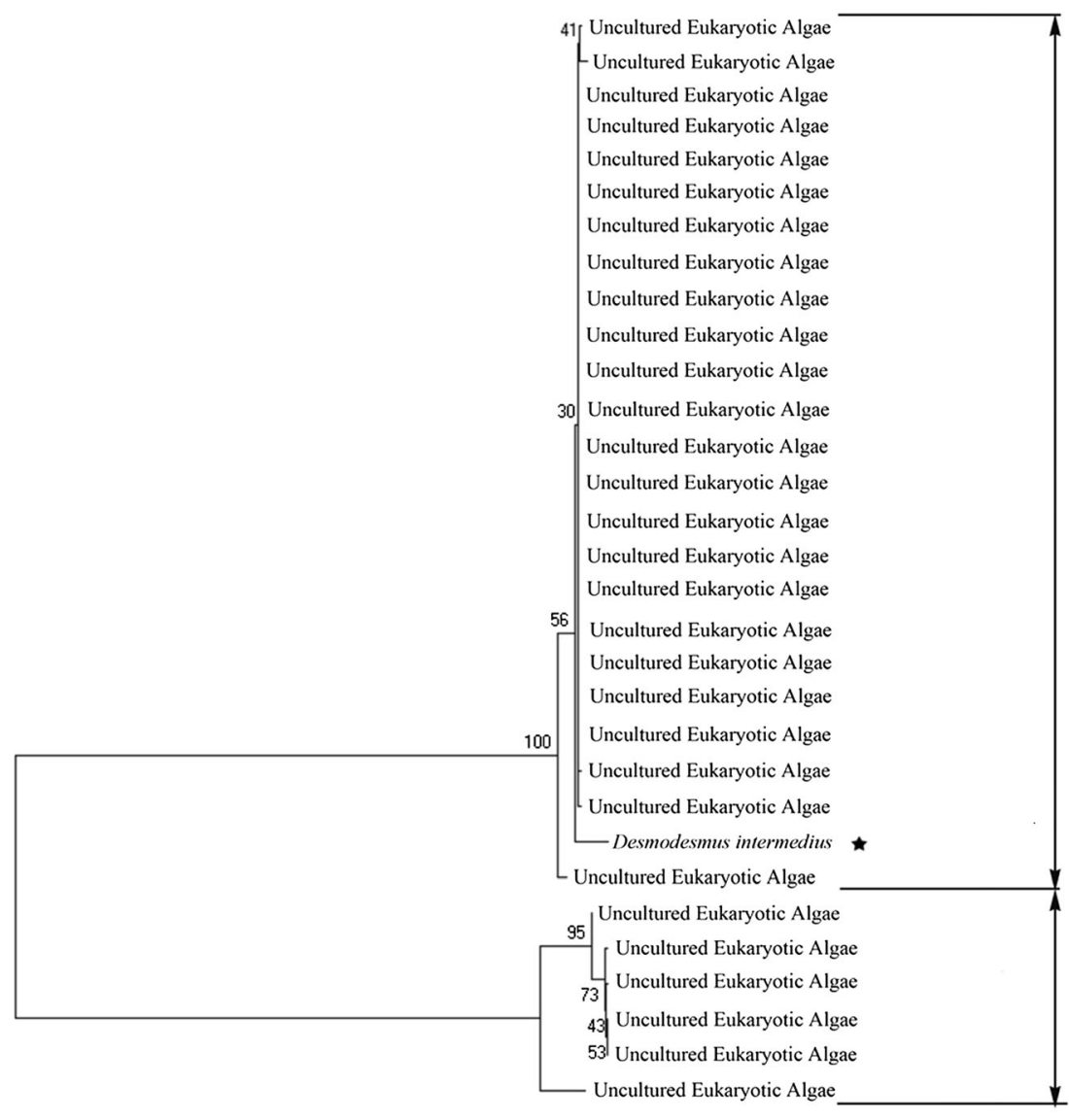




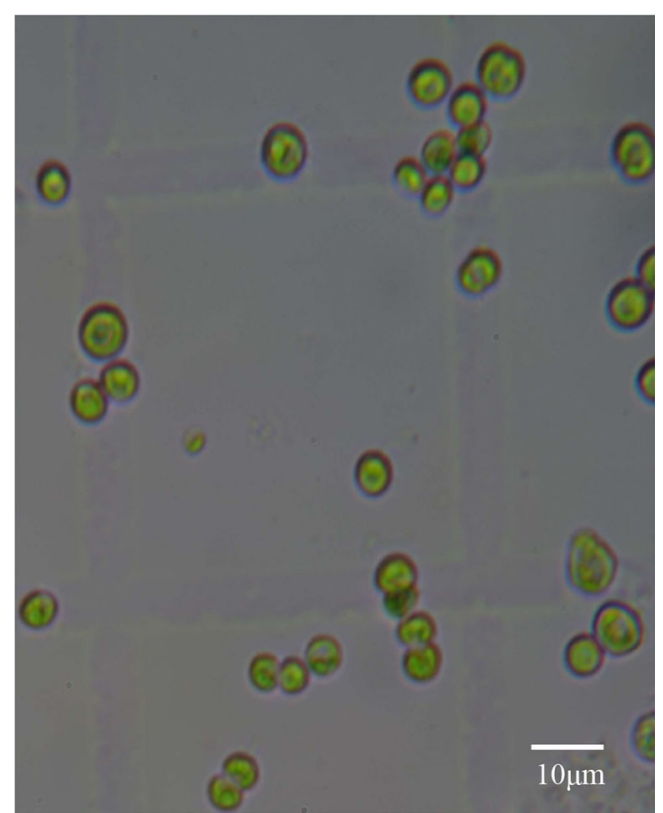

Fig. 4 Morphology of eukaryotic algae isolates of the Desmodesmus intermedius. Scale bars, $10 \mu \mathrm{m}$

Information $(\mathrm{NCBI})$ database, and the neighbor-joining tree was then constructed (Fig. 3). All of 31 sequences are compared to $18 \mathrm{~S}$ rDNA of eukaryotic algae. Thirty of them were considered as uncultured eukaryotic algae. Only one sequence was identified as D. intermedius (Fig. 3).

In addition, the phylogenetic tree also showed that uncultured eukaryotic algae belonged to two different species at least. In summary, the algae in the activated sludge of propylene oxide saponification wastewater were different from that in the municipal wastewater. There were two reasons contributed to this situation. One reason was that PO saponification wastewater was produced from the production process of propylene oxide in the chemical plant, and the components of this wastewater were stable and simple, which caused that the diversity of eukaryotic algae is low. In contrast, municipal wastewater has complex components and higher species diversity. The other reason was that most of the eukaryotic algae were annotated as unidentified eukaryotic algae in PO saponification wastewater activated sludge. There were many uncertainties of eukaryotic algae diversity.

\section{Isolation of Eukaryotic Algae}

An eukaryotic algae named JY001 was successfully isolated from PO saponification wastewater activated sludge using microorganism separation techniques (Fig. 4). Through 18S rDNA sequencing, the alga was identified as $D$. intermedius. $D$. intermedius was reported with the characteristics of thermo-tolerance, high growth rate, and high lipid content, and was often employed to produce biodiesel [14-16]. Through observed using optical microscope, D. intermedius JY001 was spherical, and the diameter of this alage was no more than $10 \mu \mathrm{m}$.

It was worth noting that we did not separate other eukaryotic algae except for D. intermedius. Most of the eukaryotic algae in the PO saponification wastewater activated sludge were uncultured and could not grow in the artificial culture. However, D. intermedius could adapt to the artificial culture environment and was isolated successfully. In order to isolate more uncultured eukaryotic algae, it is necessary to improve the medium and the culture contitions.

\section{Diversity of Eukaryotic Algae in Different Ecosystems}

The diversity of eukaryotic algae in the PO saponification wastewater activated sludge and the municipal activated sludge were compared with several different ecosystems (Table 1). In all of them, the highest abundance of algae was found in Calcifying Biofilms of Two Karstic Streams in Germany. The identified species could be divided into three classes, which were Trebouxiophyceae, Chlorophycea, and
Table 1 Diversity of eukaryotic algae in different ecosystems

\begin{tabular}{|c|c|c|c|c|}
\hline \multirow{2}{*}{$\begin{array}{l}\text { Ecosystems } \\
\text { Zoige Alpine Wetland [17] }\end{array}$} & \multirow{2}{*}{$\begin{array}{l}\text { Total } \\
23\end{array}$} & \multirow{2}{*}{$\begin{array}{l}\begin{array}{l}\text { Uncultured } \\
\text { algae }\end{array} \\
18\end{array}$} & \multicolumn{2}{|c|}{ Identified algae } \\
\hline & & & 5 & $\begin{array}{l}\text { Chlorella,Planktosphaeria, } \\
\text { Scenedesmus abundans, } \\
\text { Scenedesmus bijuga, } \\
\text { Bacillaripiophyta }\end{array}$ \\
\hline Lake taihu [18] & 14 & 12 & 2 & Cryptophyta, Bacillariophyta \\
\hline $\begin{array}{l}\text { Calcifying Biofilms of Two Karstic } \\
\text { Streams in Germany [19] }\end{array}$ & 58 & 24 & 34 & $\begin{array}{c}\text { Three classes, Trebouxiophyceae, } \\
\text { Chlorophycea,Ulvophyceae }\end{array}$ \\
\hline $\begin{array}{l}\text { Propylene Oxide Saponification } \\
\text { Wastewater Activated Sludge } \\
\text { (this rearch) }\end{array}$ & 31 & 30 & 1 & Desmodesmus intermedius \\
\hline $\begin{array}{l}\text { Municipal Wastewater Treatment } \\
\text { Plant Activated Sludge } \\
\text { (this rearch) }\end{array}$ & 9 & 4 & 5 & $\begin{array}{l}\text { Ostreococcus, Symbiodinium, } \\
\text { Anurofeca, Lotharella, } \\
\text { Thalassiosira }\end{array}$ \\
\hline
\end{tabular}


Ulvophyceae, respectively. Similar to Zoige Alpine Wetland and Lake taihu, uncultured algae dominated the majority of eukaryotic algae in the PO saponification wastewater activated sludge in our research. It was interesting that $D$. intermedius was found and successfully isolated from PO activated sludge, which was not found in other ecosystems. Further research will be carried out in order to isolate the uncultured eukaryotic algae in this activated sludge, which would be helpful to reveal the role of eukaryotic algae in the activated sludge ecosystem.

\section{Conclusions}

In this study, the eukaryotic algae communities in the activated sludge from PO saponification wastewater and municipal wastewater treatment plant were analyzed respectively. In municipal wastewater activated sludge, the algae could be divided into nine different groups. By contrast, the algae in the PO saponification wastewater activated sludge could be grouped into two unidentified groups. In order to further analyze the diversity of eukaryotic algae in the PO saponification wastewater activated sludge, 18S rDNA clone library of eukaryotic algae was constructed, and 31 clones were obtained. The phylogenetic tree also showed that eukaryotic algae from PO saponification wastewater activated sludge belonged to two different species. Based on BLASTn analysis, one of them was identified as $D$. intermedius, while others were considered to uncultured eukaryotic algae. In addition, D. intermedius was successfully isolated. This study would be helpful to understand the eukaryotic alage diversity and utilize the biodiesel-producing eukaryotic alage in PO saponification wastewater activated sludge.

Acknowledgements This work was supported by Shandong Provincial Natural Science Foundations (ZR2016CL02, ZR2016CB20), National Natural Science Foundations of China (No. 31100088, 31300045, 31600148,31600066 ), Shandong province science and technology development plan (No. 2013GSF12006), Shandong Excellent Young Scientist Award Fund (No. BS2014YY031), and Foundation of University of Jinan (XKY1324, XBS1519).

\section{Compliance with Ethical Standards}

Conflict of Interest The authors declare that they have no competing interests.

\section{References}

1. Martinez-Garcia CG, Fall C, Olguin MT (2016) Activated sludge mass reduction and biodegradability of the endogenous residues by digestion under different aerobic to anaerobic conditions: comparison and modeling. Bioresour Technol 203:32-41
2. Zhu H, Chen L, Zhang D, Zhao X (2007) Development in research methods of activated sludge bacterial community. Acta Ecol Sin 9: 314-322

3. Zhao J, Zhang H, Wang Z, Pan F, Hesham A-L, Gao Y, Zhang Y, Yang M (2015) Impacts of produced water origin on bacterial community structures of activated sludge. Microb Ecol 37:192-199

4. Wu K, Wu P, Xu Y, Li Y, Shen Y (2015a) Formation mechanism of aerobic granular sludge and removal efficiencies in integrated ABR-CSTR reactor. Huan Jing Ke Xue 36:2947-2953

5. Shchegolkova NM, Krasnov GS, Belova AA, Dmitriev AA, Kharitonov SL, Klimina KM, Melnikova NV, Kudryavtseva AV (2016) Microbial community structure of activated sludge in treatment plants with different wastewater compositions. Front Microbiol 7:90

6. Kim HY, Jeon J, Yu S, Lee M, Kim TH, Kim SD (2013) Reduction of toxicity of antimicrobial compounds by degradation processes using activated sludge, gamma radiation, and UV. Chemosphere 93: 2480-2487

7. Andersen RA (1992) Diversity of eukaryotic algae. Biodivers Conserv 1:267-292

8. Li S, Zhou J, Wei L, Kong F, Shi X (2015) A review of diversity of freshwater picophytoplankton and its related research methods. Chinese J Ecol 34:1174-1182

9. Li C, Xiao S, Ju LK (2016) Cultivation of phagotrophic algae with waste activated sludge as a fast approach to reclaim waste organics. Water Res 91:195-202

10. Li D (2001) Analysis of methods to biologically treat waste water from saponification in propylene epoxide production. Lv Jian Gong Ye 8:36-39

11. Cheung MK, Au CH, Chu KH, Kwan HS, Wong CK (2010) Composition and genetic diversity of picoeukaryotes in subtropical coastal waters as revealed by 454 pyrosequencing. ISME J 4:1053-1059

12. Dong S (2013) Eukaryotic algal-biased PCR and its application. Dissertation, University of Chinese Academy of Sciences

13. Zheng C, Wang G, Liu J, Song C, Gao H, Liu X (2013) Characterization of the major capsid genes (g23) of T4type bacteriophages in the wetlands of northeast China. Microb Ecol 65:616-625

14. $\mathrm{Wu} \mathrm{L}, \mathrm{Xu} \mathrm{L}, \mathrm{Hu} \mathrm{C}$ (2015b) Screening and characterization of oleaginous Microalgal species from Northern Xinjiang. J Microbiol Biotechnol 25:910-917

15. Lürling M (2009) Phenotypic plasticity in the green algae Desmodesmus and Scenedesmus with special reference to the induction of defensive morphology. Ann Limnol-Int J Lim 39:85-101

16. Pan YY, Wang ST, Chuang LT, Chang YW, Chen CNN (2011) Isolation of thermo-tolerant and high lipid content green microalgae: oil accumulation is predominantly controlled by photosystem efficiency during stress treatments in Desmodesmus. Bioresour Technol 102:10510-10517

17. Chen X, Liu R, Wang Y, Zhang H (2012) Research on algal diversity in Zoige alpine wetland. Huan Jing Ke Xue 8:979-986

18. Xie W, Wang Z, Kong F, Shi X (2012) Genetic diversity of photosynthetic picoeukaryotes in Lake taihu. J Lake Sci 6:123-128

19. Hodač L, Brinkmann N, Mohr KI, Arp G, Hallmann C, Ramm J, Spitzer K, Friedl T (2015) Diversity of microscopic green algae (Chlorophyta) in calcifying biofilms of two Karstic streams in Germany. Geomicrobiol J 32:275-290 